\title{
Maskability of visual targets varying in brightness contrast
}

\author{
WILLIAM N. DEMBER and JOHN CHAMBERS \\ University of Cincinnati, Cincinnati, Ohio 45221
}

\begin{abstract}
Duration thresholds of visual targets varying in brightness contrast were measured under backward masking and nonmasking conditions. As expected, thresholds varied as a function of target contrast in the nonmasking condition; thresholds were elevated for all targets in the masking condition. These results bear on the interpretation of a previously reported finding that targets with increasing numbers of internal contours were both increasingly hard to detect and hard to mask. The attribution of that finding to mechanisms underlying contour interaction continues to be worthy of consideration: in particular, the previous results do not reflect a general relation between target detectability and target maskability.
\end{abstract}

In previous papers (Cox \& Dember, 1970; Dember, Mathews, \& Stefl, 1973; Dember \& Stefl, 1972; Dember, Stefl, \& Kao, 1974; Ellis \& Dember, 1971; Sherrick \& Dember, 1970), we reported a relation between the (backward) maskability of certain visual targets and their detectability under nonmasking conditions. The targets were disk-shaped, with varying numbers of internal black and white segments. Duration thresholds were measured under nonmasking "control" conditions and also when the target was followed by a pair of black rings; one ring of the pair fit snugly around the target disk and the other served as the "alternative" for a two-alternative, spatial forced-choice indicator response.

The relation of interest has been characterized as follows: As number of target segments increases (up to some limiting value) the targets become increasingly difficult to detect but also increasingly difficult to mask. Moreover, certain targets seem unmaskable and the detectability of others is even enhanced by the presence of the masking stimulus.

The present experiment was designed to explore further the specificity of the relation stated above, which is phrased in terms of number of target segments. One can ask whether number of segments is the right way to identify the independent variable. Perhaps the relation is more general than that; if so, attempts to account for these startling results in terms of mechanisms tied to segments per se or to contour interactions are likely to be fruitless. Perhaps varying number of target segments is simply one way of manipulating target detectability, and the relation in question can better be characterized as follows: targets that are difficult to detect are also difficult to mask. Stated in that form, the relation appears exceedingly counterintuitive. And if that way of characterizing the earlier results proves invalid, then the original conception of the independent variable as being directly

This research was supported by Grant GB-33621 from the National Science Foundation to William N. Dember. Request for reprints should be sent to William N. Dember, Department of Psychology, University of Cincinnati, Cincinnati, Ohio 45221. related to target segments will be greatly strengthened.

In the present experiment target detectability was manipulated by varying the brightness contrast between the target and its background. Duration thresholds were measured, as in the previous experiments, under both nonmasking and masking conditions. We expected that, with this method of manipulating target detectability, the previous results would not obtain. Rather, target duration threshold should increase as brightness contrast decreases under both nonmasking and masking conditions. The masking stimulus should uniformly elevate the thresholds of all the targets.

\section{METHOD}

\section{Subjects}

The subjects were four male and four female college students, who were paid for participation. All had normal vision or were corrected to normal with glasses or contacts; all were naive about the purpose of the experiment.

\section{Stimuli}

The stimuli were presented tachistoscopically (Scientific Prototype, Model GX); viewing was monocular. The target stimuli consisted of five disks, each $8 \mathrm{~mm}$ in diam (subtending $23.5 \mathrm{~min}$ of arc). The disks were cut from paper varying in reflectance; each was mounted on a gray background which reflected $50 \%$ of the incident light.

With the gray background paper alone in place, each of three fields of the tachistoscope was set to yield a measured luminance of $10 \mathrm{fL}$. The five shades of gray used for the target disks were calibrated by measuring the luminance of the target field with each of the shades of gray filling the entire visual field. Luminance measurements were made with a Spectra brightness spot meter. Measured in this way, the luminance values of the five shades of gray were, from darkest to lightest, $0.7,1.4,2.5$, 4.5 , and $6.5 \mathrm{fL}$. Target-to-background contrast was computed by dividing those values by 10 (the luminance of the background).

The masking stimulus consisted of two rings. The inner diameter of each ring was $8 \mathrm{~mm}$; the outer diameter was $16 \mathrm{~mm}$. The ring centers were $20 \mathrm{~mm}$ apart (58.9 min of arc). The rings were cut from the same paper as the darkest disk $(0.7 \mathrm{fL})$ and were mounted on the same gray paper as the targets.

\section{Procedure}

The subject's task on each trial was to locate the target disk, 
guessing if necessary, as having been within either the left or the right ring (or in the nonmasking condition, as having been either in the left or the right half of the field). Target location was randomly varied. A trial consisted of the following sequence: adaptation field-target field-masking field-adaptation field. The trial was initiated by the subject, on signal from the experimenter, by depressing a switch. The onset of the masking field coincided with the termination of the target field. Masking-field duration was $105 \mathrm{msec}$. Target-field duration varied according to the requirements of the psychophysical method employed, the double staircase variant of the method of limits.

The staircase method was used to obtain a duration threshold for each subject in each of the 10 experimental conditions (five target stimuli by presence or absence of masking rings in the masking field). A given "staircase" consisted of an ascending and a descending series, randomly intermixed to preclude errors of anticipation. On each series, the following rule was applied: if the subject was incorrect in locating the target, target duration was increased by $.5 \mathrm{msec}$ for the next trial of that series; if the subject was correct on two successive trials, target duration was decreased by $.5 \mathrm{msec}$ for the next trial of that series. The first 15 trials of each staircase were used to obtain a rough estimate of the threshold value. The remaining 70 trials were used in the calculation of the threshold, according to the procedure outlined by Dixon and Massey (1969).

Two such threshold determinations were conducted per day for 5 days. A 10-min rest period, followed by a 5-min dark adaptation period, separated the two daily testing sessions. The first session was preceded by a 5-min dark adaptation period. Prior to the 5 testing days, each subject was given 2 days of practice with the psychophysical procedure. A separate random order of testing conditions was used for each subject.

\section{RESULTS AND DISCUSSION}

The mean duration threshold, averaged over the eight subjects, is given in Table 1 for each of the 10 conditions. A repeated measures, two-way analysis of variance revealed both main effects to be significant: thresholds were higher in the masking than in the nonmasking condition $(\mathrm{F}=86.30 ; \mathrm{p}<.01)$, and thresholds varied with variation in target-background contrast $(F=48.97 ; \mathrm{p}<.01)$. In addition, the interaction between the two variables was significant $(F$ $=6.16 ; \mathrm{p}<.01$ ).

Inspection of the data indicates quite clearly that our expectation was confirmed. As contrast decreases, threshold increases in both the nonmasking and the
Table 1

Mean Duration Threshold (Milliseconds) as a Function of Target Contrast and Masking Condition

\begin{tabular}{lrrrrr}
\hline & \multicolumn{5}{c}{ Brightness Contrast of Target* } \\
\cline { 2 - 6 } Condition & .07 & .14 & .25 & .45 & .65 \\
\hline No Mask & 6.75 & 6.44 & 7.84 & 10.14 & 16.85 \\
Mask & 17.20 & 20.88 & 24.26 & 27.96 & 36.60 \\
\hline
\end{tabular}

*Note that as contrast values approach 1.0, the target becomes increasingly indiscriminable from its background.

masking condition. The interaction effect indicates that, if anything, the hard-to-detect, low contrast targets were even more vulnerable to masking than were the easy-to-detect, high contrast targets. In our previous experiments using targets with internal contours, the significant interaction effect took the opposite direction, That is, the hard-to-detect targets in the nonmasking condition were also relatively harder to mask. The present results quite convincingly show that our attribution of the earlier findings to some mechanisms tied to contour interaction warrants continued consideration. The earlier results very definitely cannot be viewed as a manifestation of a general relation between nonmasking target detectability and target maskability.

\section{REFERENCES}

Cox, S. I., \& Dember, W. N. Backward masking of visual targets with internal contours. Psychonomic Science, 1970, 19, 255-256.

Dember, W. N., Mathews, W. D., \& Stefl, M. Backward masking and enhancement of multisegmented visual targets. Bulletin of the Psychonomic Society, 1973, 1, 45-47.

Dember, W. N., \& Stefl, M. Backward enhancement? Science, 1972, $175,93-93$.

Dember, W. N., Stefl, M., \& Kao, K. C. Backward masking of gratings varying in spatial frequency. Bulletin of the Psychonomic Society, 1974, 3, 439-441.

Dixon, J. W., \& Massey, F. J.Introduction to statistical analysis. New York: McGraw-Hill, 1969.

Ellis, D., \& Dember, W. N. Backward masking of visual targets with internal contours: A replication. Psychonomic Science, $1971,22,91-92$.

Sherrick, M. F., \& Dember, W. N. Visual backward masking and the area-detection relation. Psychonomic Science, 1971, 22, 91-92.

(Received for publication October 21, 1974.) 